\title{
ICAM-1 Deficiency Exacerbates Sarcoid-Like Granulomatosis Induced by Propionibacterium acnes through Impaired IL-10 Production by Regulatory T Cells
}

\author{
Masahiro Kamata, Yayoi Tada, Aya Mitsui, Sayaka Shibata, Tomomitsu Miyagaki, Yoshihide Asano, Makoto Sugaya, \\ Takafumi Kadono, and Shinichi Sato
}

\author{
From the Department of Dermatology, Faculty of Medicine, University of Tokyo, Tokyo, Japan
}

CME Accreditation Statement: This activity ("ASIP 2013 AJP CME Program in Pathogenesis") has been planned and implemented in accordance with the Essential Areas and policies of the Accreditation Council for Continuing Medical Education (ACCME) through the joint sponsorship of the American Society for Clinical Pathology (ASCP) and the American Society for Investigative Pathology (ASIP). ASCP is accredited by the ACCME to provide continuing medical education for physicians.

The ASCP designates this journal-based CME activity (“ASIP 2013 AJP CME Program in Pathogenesis") for a maximum of 48 AMA PRA Category 1 Credit(s) ${ }^{\top M}$. Physicians should only claim credit commensurate with the extent of their participation in the activity.

CME Disclosures: The authors of this article and the planning committee members and staff have no relevant financial relationships with commercial interests to disclose.

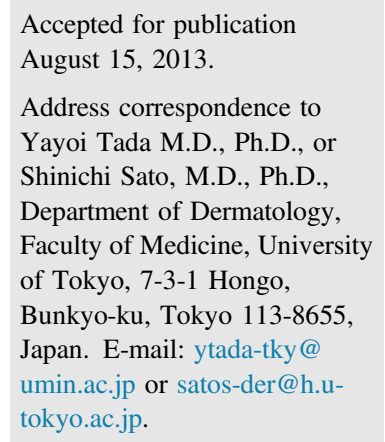

\begin{abstract}
Propionibacterium acnes has been implicated as one of the suggested causative antigens for sarcoidosis, a systemic granulomatous disease. By injecting heat-killed $P$. acnes into the dorsal skin of C57BL/6J mice on days $1,3,5$, and 14, sarcoid-like granulomatosis was induced in skin and lungs of these mice on day 28. To clarify the role of cell adhesion molecules in cutaneous sarcoidosis, we induced sarcoidlike granulomatosis in mice deficient of intercellular adhesion molecule (ICAM)-1, L-selectin, P-selectin, or E-selectin via repeated $P$. acnes injection. Histopathologic analysis revealed that granuloma formation was aggravated in the skin and lungs of ICAM-1-deficient mice compared with wild-type mice. Within skin granulomas of ICAM-1-deficient mice, $P$. acnes immunization up-regulated mRNA expression of tumor necrosis factor- $\alpha$, although it failed to induce IL-10 mRNA expression in contrast to wild-type mice. Infiltration of regulatory T cells into skin granuloma was similar between wild-type mice and ICAM-1-deficient mice. P. acnes immunization induced IL-10 production by $\mathrm{CD}_{4}^{+} \mathrm{CD} 25^{+} \mathrm{Foxp} 3^{+}$ regulatory $T$ cells in lymph nodes of wild-type mice in vivo, which was absent in regulatory $T$ cells of ICAM-1-deficient mice. Our results indicate that ICAM-1 is imperative for inducing regulatory T cells to produce IL-10 in vivo, which would prevent granuloma formation. (Am J Pathol 2013, 183:1731-1739; http://dx.doi.org/10.1016/j.ajpath.2013.08.021)
\end{abstract}

Sarcoidosis is a systemic granulomatous disease characterized by a variable clinical presentation and course. Although numerous organs may be involved, lungs, lymph nodes, and skin are most commonly affected. However, the cause of sarcoidosis is unknown. ${ }^{1}$ Some of the earliest studies on sarcoidosis reported the involvement of Chlamydia or Borrelia. ${ }^{2,3}$ Recently, sarcoidosis has been reported to be associated with exposure to various microbial agents and environmental substances. $^{4-7}$ Although it has been indicated that mycobacterial infection is related to sarcoidosis because of their clinical and immunopathologic similarities, their association remains controversial. $^{8-10}$ Propionibacterium acnes, an anaerobic, non-spore-forming, gram-positive rod bacterium, has been implicated as one of the suggested causative antigens for sarcoidosis because this bacterium could be isolated from sarcoid lesions. ${ }^{11}$ Some studies using quantitative real-time PCR have revealed markedly higher levels of $P$. acnes genomes in the mediastinal or superficial lymph nodes of sarcoid patients than in those of controls, suggesting that there is an intrinsic

Supported by grants from the Ministry of Education, Culture, Sports, Science, and Technology of Japan. 
infection of $P$. acnes in patients with sarcoidosis. ${ }^{12-14}$ Nishiwaki et al ${ }^{15}$ observed that an immune response against indigenous $P$. acnes already exists in the healthy lung. They also demonstrated that expansion of the numbers of recirculating $P$. acnes - primed cells, produced by extrapulmonary sensitization, can specifically cause granulomatous changes of the lung, sharing several similarities with pulmonary sarcoidosis, even in the absence of antigen anchoring. ${ }^{15}$ In any case, sarcoidosis granuloma involves infiltration of leukocytes, predominantly macrophages.

In general, leukocyte recruitment into inflammatory sites is achieved using constitutive or inducible expression of multiple cell adhesion molecules. ${ }^{16}$ L-selectin (CD62L), E-selectin (CD62E), and P-selectin (CD62P) primarily mediate leukocyte capture and rolling on the endothelium. ${ }^{17}$ L-selectin is constitutively expressed by most leukocytes. ${ }^{17}$ Although P-selectin is rapidly mobilized to the surface of activated endothelium or platelets, E-selectin expression is induced within several hours after activation with inflammatory cytokines. ${ }^{17}$ Intercellular adhesion molecule (ICAM)-1 (CD54), a member of the immunoglobulin superfamily, is constitutively expressed not only on endothelial cells but also on fibroblasts and epithelial cells. ${ }^{18}$ It can be up-regulated transcriptionally by several proinflammatory cytokines, such as tumor necrosis factor (TNF)- $\alpha$, interferon (IFN)- $\gamma$, and IL-1. ${ }^{18}$ ICAM-1 forms the counterreceptor for the lymphocyte $\beta_{2}$-integrins, such as lymphocyte function-associated antigen (LFA)-1. ${ }^{16}$ The ICAM-1/LFA-1 interaction predominantly mediates firm adhesion and transmigration of leukocytes at sites of inflammation. ${ }^{16}$ In addition to its key role in the context of leukocyte adhesion, locomotion, and migration, ICAM-1/LFA-1 interaction also functions as a co-stimulatory signal for T-cell activation. ${ }^{19-21}$ Even a high density of T-cell receptors-major histocompatibility complexantigen complex could not compensate for the lack of ICAM-1/ LFA-1 interaction for $\mathrm{CD} 4{ }^{+}$T-cell activation. ${ }^{22}$

Although these cell adhesion molecules play important roles in leukocyte transmigration, the way each molecule contributes to cell infiltration is complex. Inhibition or absence of adhesion molecules has been associated with reduction in inflammation and its sequelae, consistent with a central role for leukocytes in promoting inflammation. ${ }^{23-29}$ In contrast, some studies using adhesion molecule-deficient mice have reported exacerbation of leukocyte recruitment and inflammation. ${ }^{30-33}$ In this case, there may be a possibility that the absence of certain key adhesion molecules reduces recruitment of leukocytes that inhibit inflammation, namely, regulatory $\mathrm{T}$ cells (Tregs). Moreover, ICAM-1 deficiency or suppression of its function can affect inflammation through impaired activation or differentiation of $\mathrm{T}$ cells as a result of a lack of costimulatory signaling. Indeed, lack of ICAM-1 on antigenpresenting cells (APCs) leads to poor T-cell activation and proliferation both in vitro and in vivo, resulting in poor generation of central memory $\mathrm{T}$ cells. ${ }^{34}$

In this study, we examined the role of cell adhesion molecules, such as ICAM-1, L-selectin, P-selectin, and E-selectin, in the $P$. acnes-induced sarcoidosis model, using mice deficient in these molecules. Remarkably, in $I C A M-1^{-/-}$mice, skin and lung granuloma formation was aggravated without showing a defect in Treg infiltration into the skin. Compared with wild-type mice, ICAM-1 ${ }^{-/}$mice showed reduced IL-10 production by Tregs, indicating the essential role of ICAM-1 in the suppression of skin granuloma formation by Tregs through induction of an anti-inflammatory mediator, IL-10.

\section{Materials and Methods}

Mice

L-selectin-deficient $\left({\mathrm{L}-\text { selectin }^{-/}}^{-}\right)$mice were provided by Thomas F. Tedder and were previously described in their article. ${ }^{35}{\text { ICAM }-1^{-1-}, \mathrm{P}-\text { selectin }^{-1-} \text {, and E-selectin }}^{-1-}$ mice were obtained from The Jackson Laboratory (Bar Harbor, $\mathrm{ME})$. All mice were backcrossed 10 generations onto the C57BL/6 genetic background. Mice used for experiments were 6 to 10 weeks old. Body size and lung size were similar in mutant and wild-type mice (data not shown). All mice were housed in a pathogen-free barrier facility and screened regularly for pathogens. All studies and procedures were approved by the Committee on Animal Experimentation of University of Tokyo.

\section{Heat-Killed $P$. acnes Injection}

P. acnes (ATCC, Manassas, VA) was dissolved in PBS at a concentration of $10^{9} / \mathrm{mL}$ and heat-killed at $85^{\circ} \mathrm{C}$ for $10 \mathrm{mi}-$ nutes. One hundred microliters of heat-killed $P$. acnes or PBS was injected subcutaneously into the shaved back skin of the mice on days 1, 3, 5, and 14 (Supplemental Figure S1).

\section{Histopathologic Assessment of Skin and Lung Granulomas}

Morphologic characteristics of skin and lung sections were assessed under a light microscope. All skin and lung samples were taken on day 28 after $P$. acnes or PBS injection. Skin samples were obtained from the nodular region on the dorsal skin into which P. acnes or PBS had been injected on day 14 . Sections were stained with H\&E. The skin granulomas were relatively circumscribed. We measured the thickest part of

Table 1 Grading Scale for Evaluation of Lung Granuloma Formation

\begin{tabular}{ll}
\hline $\begin{array}{l}\text { Grade of } \\
\text { granuloma }\end{array}$ & Histologic features \\
\hline 0 & Normal lung \\
1 & Inflammation without granuloma formation \\
2 & Mild granuloma formation with definite damage \\
& to lung structure and formation \\
3 & Moderate granuloma formation with definite \\
& damage to lung structure and formation \\
4 & Severe distortion of structure and large \\
& granuloma areas \\
\hline
\end{tabular}


the granuloma vertical to the epidermis in each section (Supplemental Figure S2). The severity of lung granuloma was semiquantitatively assessed according to a grading scale (Table 1), referring to fibrosis assessment as described previously $^{36}$ : the lung granuloma was graded on a scale of 0 to 4 by examining randomly chosen fields of the left middle lobe at a magnification of $\times 100$. Data were obtained from six to eight mice per group. All of the sections were scored independently by two masked investigators.

\section{Immunohistochemical Staining}

Paraffinized tissue sections of skin and lung taken from $P$. acnes-injected mice were deparaffinized and stained with rat anti-mouse F4/80 monoclonal antibodies (Abs; Serotec, Oxford, United Kingdom) or rat anti-mouse Foxp3 monoclonal Abs (eBioscience, San Diego, CA) using VECTASTAIN ABC Rat IgG Kit (Vector Laboratories, Burlingame, CA) according to the manufacturer instructions. Foxp3positive cells in skin were counted in three random grids per mice under magnification of $\times 400$ high-power fields. Data were obtained from six mice per group. Each section was examined independently by 2 masked investigators.

\section{RNA Isolation and Real-Time PCR}

Total RNA was isolated from tissue using RNeasy fibrous tissue kit (Qiagen, Crawley, United Kingdom). Granuloma tissue that was confirmed as a nodule macroscopically was obtained for $P$. acnes-injected skin samples. Total RNA from each sample was reverse-transcribed into cDNA using TaqMan Reverse Transcription Reagents (Invitrogen, Carlsbad, CA). Expression of TNF- $\alpha$, IFN- $\gamma$, IL-2, IL-4, IL10, and IL-12 was analyzed by a StepOnePlus Real Time PCR System (Applied Biosystems, Carlsbad, CA) using a real-time PCR quantification method according to the manufacturer instructions. Sequence-specific primers and probes were designed by TaqMan Gene Expression Assays (Applied Biosystems). All samples were analyzed in parallel with $G A P D H$ gene expression as an internal control. The relative change in the levels of the genes of interest was determined by the $2^{-\triangle \Delta \mathrm{CT}}$ method.

\section{Flow Cytometry}

A single cell suspension of spleen or lymph nodes was obtained by gentle teasing with forceps and 27 -gauge needles, followed by filtering through a nylon mesh. Erythrocytes were lyzed by treatment with ammonium chloride, and the cells were resuspended in BD PharmingenStain Buffer (BD Biosciences, Franklin Lakes, NJ). The cells were first incubated with the respective monoclonal $\mathrm{Abs}$ at 1:20 dilution at $4^{\circ} \mathrm{C}$ for 20 minutes and then with the respective second monoclonal Abs at 1:40 dilution for the next 30 minutes. The final suspension was made in $500 \mu$ Lof BD PharmingenStain Buffer for analysis. Abs used for analysis via flow cytometry are as follows: APC-conjugated rat antimouse CD4 monoclonal Abs (BioLegend, San Diego, CA), phycoerythrin $(\mathrm{PE})-$ conjugated rat anti-mouse $\mathrm{CD} 25$ monoclonal Abs (BioLegend), Alexa Fluor 488-conjugated rat anti-mouse Foxp3 monoclonal Abs (BioLegend), PECy7-conjugated rat anti-mouse CD11a Abs (Abcam, Cambridge, MA), and peridinin chlorphyll protein (PerCP)-Cy5.5-conjugated rat anti-mouse IL-10 monoclonal Abs (eBioscience). $\mathrm{CD} 3^{+} \mathrm{CD} 25^{+} \mathrm{Foxp}^{+}$Tregs in splenocytes were stained using Mouse Treg Flow Kit (BioLegend) according to the manufacturer instructions. Flow cytometry was performed using BD FACSVerse (BD Biosciences).

\section{Intracellular IL-10 Expression Analysis in Tregs in Inguinal Lymph Nodes}

Inguinal lymph node cells from P. acnes- or PBS-injected mice were cultured for 2 days in RPMI 1640 complete medium supplemented with $10 \%(\mathrm{v} / \mathrm{v})$ fetal bovine serum, 2 $\mathrm{mmol} / \mathrm{L} \mathrm{L}$-glutamine, $100 \mathrm{U} / \mathrm{mL}$ of penicillin, and $100 \mu \mathrm{g} / \mathrm{mL}$ of streptomycin at a density of $1 \times 10^{6}$ cell $/ \mathrm{mL}$ ( $2 \mathrm{~mL}$ per well) in a 24-well culture plate, under stimulation of $5 \mu \mathrm{g} / \mathrm{mL}$ of plate-bound anti-mouse CD3 Abs NA/LE (BD Biosciences) and $1 \mu \mathrm{g} / \mathrm{mL}$ of soluble anti-mouse CD28 Abs (BD Biosciences). Cells were fixed, permeabilized, and stained with Abs using a BD Cytofix/CytoPerm Fixation/Permeabilization Kit (BD Biosciences) according to the manufacturer instructions. Briefly, cultured cells were stimulated with a leukocyte activation cocktail and incubated with $2 \mu \mathrm{L} / \mathrm{mL}$ of BD GolgiPlug (BD Biosciences) for 4 hours. Cells were washed and incubated with APC-conjugated anti-mouse CD4 monoclonal $\mathrm{Abs}$ and $\mathrm{PE}-$ conjugated anti-mouse $\mathrm{CD} 25$ monoclonal $\mathrm{Abs}$ at $4^{\circ} \mathrm{C}$ for 20 minutes. Cells were fixed, permeabilized, and then stained with Alexa Fluor 488conjugated anti-mouse Foxp3 monoclonal Abs and PerCPCy5.5-conjugated anti-mouse IL-10 monoclonal Abs or isotype control. These cells were analyzed by BD FACSVerse.

\section{Statistical Analysis}

All data are expressed as means \pm SD or SEM. Statistical analysis was performed using the Wilcoxon rank sum test for comparison between two groups.

\section{Results}

\section{Repeated $P$. acnes Injection into the Skin Induces} Systemic Granulomatosis

We induced systemic granulomatosis by injecting heatkilled $P$. acnes into the dorsal skin of wild-type mice as described in Materials and Methods. As shown in Figure 1, distinct granulomas were formed in both skin and lungs of mice injected with $P$. acnes but not in mice injected with PBS. Immunohistochemical analyses revealed that the 

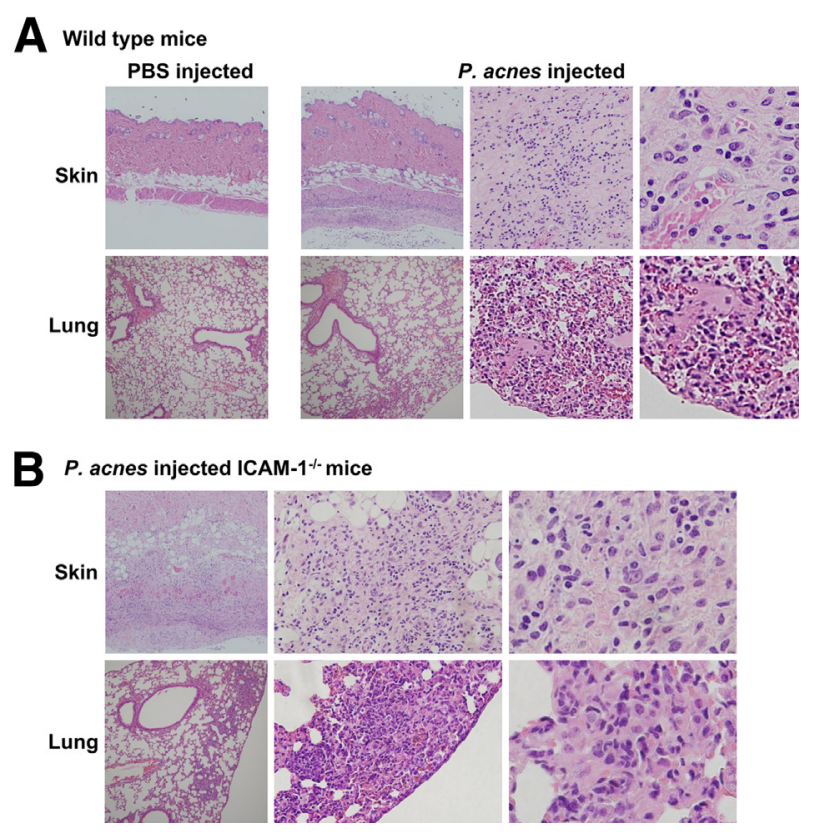

Figure 1 Granuloma formation on day 28 in skin and lungs of wild-type mice (A) and $I C A M-1^{-/-}$mice (B) injected with PBS or P. acnes. H\&E staining of the skin and lung granuloma is shown. Original magnification: $\times 100$ (A; PBS-injected mice) and $\times 100, \times 200, \times 400$ (A and $\mathbf{B}_{\text {; }}$ $P$. acnes-injected mice; left to right).

typical granulomas consisted of $\mathrm{F} 4 / 80^{+}$macrophages (data not shown). Thus, repeated injection into the dorsal skin of mice with $P$. acnes induced not only skin granuloma but also lung granulomatosis, resembling sarcoidosis.

\section{Effect of Cell Adhesion Molecules on Granuloma Formation in Skin and Lungs of $P$. acnes-Injected Mice}

We next examined the role of cell adhesion molecules in granuloma formation using mice deficient in adhesion molecules. We injected PBS or P. acnes into the dorsal skin of E-

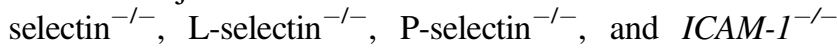
mice on days 1, 3, 5, and 14, as described above. Skin and lung samples were collected on day 28 , and histologic sections were made. There were no granulomas in the skin or lungs of PBSinjected mice, whereas granuloma was observed in $P$. acnes-injected mice. As shown in Figure 1, granuloma formation in the skin seemed most exacerbated in $P$. acnes-injected ICAM-1 ${ }^{-\prime-}$ mice compared with other mice, showing thicker granuloma formation. Granuloma formation in the lung seemed to be prominent in E-selectin ${ }^{-1-}$, Lselectin $^{-1-}$, and ICAM-1 ${ }^{-1-}$ mice compared with the others.

To quantitatively analyze granuloma formation, we performed histologic analyses. For skin, we measured the thickness of the granuloma, and for lungs, we used a grading scale for histopathologic assessment of granuloma formation (Table 1). $P$. acnes-injected $I C A M-1^{-1-}$ mice presented significantly thicker skin granuloma compared with $P$. acnes-injected wildtype mice (Figure 2A). For lungs, the granuloma scores were high in $P$. acnes-injected E-selectin ${ }^{-/}, P$. acnes-injected Lselectin $^{-/-}$, and $P$. acnes-injected $I C A M-1^{-/}$mice compared with $P$. acnes-injected wild-type mice (Figure 2B). These results demonstrated that granuloma formation was aggravated in both skin and lungs of $P$. acnes-injected $I C A M-1^{-1-}$ mice compared with $P$. acnes-injected wild-type mice. Therefore, we focused on examining the role of ICAM-1 in granuloma formation.

\section{Increased TNF- $\alpha$ Expression and Decreased IL-10} Expression in the Skin Granuloma of $P$. acnes-Injected ICAM-1 ${ }^{-/-}$Mice Compared with Wild-Type Mice

We next examined the mRNA levels of TNF- $\alpha$, IFN- $\gamma$, IL-2, IL-4, IL-10, and IL-12 in the skin granuloma on day 28 by quantitative real-time PCR analysis. TNF- $\alpha$ mRNA expression was significantly up-regulated in skin granuloma of $P$. acnes-injected wild-type mice compared with PBSinjected wild-type mice (Figure 3A). After P. acnes injection, ICAM $-1^{-1-}$ mice exhibited significantly augmented TNF- $\alpha$ mRNA expression relative to wild-type mice. In contrast, although IL-10 mRNA expression was significantly up-regulated in skin granuloma of $P$. acnes-injected
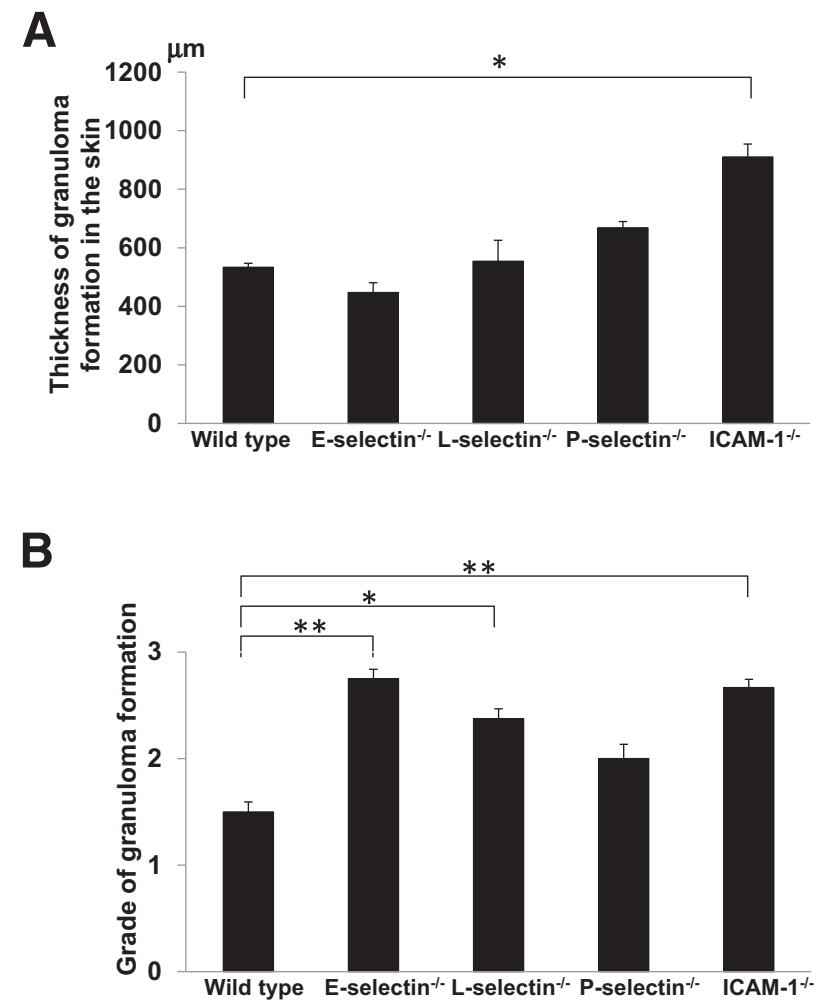

Figure 2 Evaluation of granuloma formation in the skin and lungs of wild-type, E-selectin ${ }^{-/}$, L-selectin ${ }^{-/-}$, P-selectin ${ }^{-/}$, and ICAM-1 ${ }^{-/-}$mice injected with PBS or $P$. acnes. A: Thickness of granuloma formation in the skin from $P$. acnes-injected mice. Granuloma formation on day 28 in the skin was assessed by measuring the thickness of the granuloma on the dorsal skin that had been injected with $P$. acnes on day 14. B: Grade of granuloma formation in the lung from $P$. acnes-injected mice. The severity of granuloma formation in the lungs was evaluated using a grading scale as described in Materials and Methods. Data were obtained from six to eight mice per group. Values are presented as means \pm SEM. ${ }^{*} P<0.05,{ }^{*} P<<$ 0.01 versus wild-type mice. 


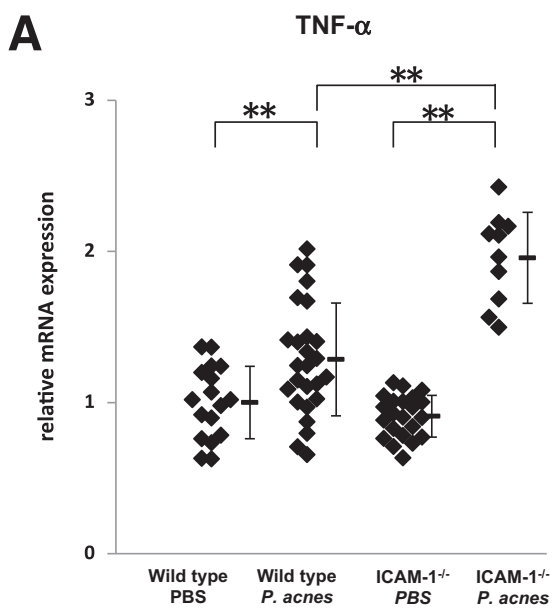

B



Figure 3 Quantitative real-time PCR analysis of TNF- $\alpha$ and IL-10 mRNAs in the skin of wild-type and ICAM-1 ${ }^{-/-}$mice that had been injected with PBS or $P$. acnes. Mice were injected with PBS or $P$. acnes, and total RNA was isolated from skin granuloma on day 28. mRNA levels for TNF- $\alpha$ (A) and IL-10 (B) were determined by quantitative real-time PCR. Data are presented as means \pm SD. ND, not detected. ${ }^{*} P<0.01$ versus wild-type mice.

wild-type mice compared with PBS-injected wild-type mice, IL-10 mRNA expression was not detected in skin granuloma of $P$. acnes-injected $I C A M-1^{-1-}$ mice (Figure $3 \mathrm{~B}$ ). IFN- $\gamma$, IL-2, and IL-12 mRNA expressions were hardly detected in the skin of PBS- and P. acnes-injected wildtype mice and $I C A M-1^{-1-}$ mice (data not shown). IL-4 mRNA expression was not detected in any of the skin samples (data not shown). These results indicated that exacerbated skin granuloma formation in $P$. acnes-injected ICAM- $1^{-/-}$mice might be due to increased TNF- $\alpha$ expression and decreased IL-10 expression in the skin granuloma of these mice.

Comparable Number of Tregs Infiltrating into the Skin Granuloma Between $P$. acnes-Injected Wild-Type Mice and ICAM-1 ${ }^{-/-}$Mice

Because Tregs are known to be one of the major cell sources of IL-10 during skin inflammation, we first evaluated the number of Foxp $3^{+}$Tregs infiltrating into the skin granuloma. Cells positively stained with anti-Foxp3 $\mathrm{Ab}$ in the skin granuloma were counted in three random grids per mice under a magnification of $\times 400$ high-power fields (Figure 4A). Skin specimens were isolated from six separate mice, and the mean number was calculated. Although the number of infiltrating Tregs into the skin granuloma of P. acnes-injected ICAM-1 ${ }^{--}$ mice tended to be lower than that in $P$. acnes-injected wildtype mice, the difference was not significant (Figure 4B). Consistent with this, there was no difference in Foxp3 mRNA level in the skin granuloma between these mice (data not shown). Thus, there was no difference in the number of infiltrating Tregs between $P$. acnes - injected $I C A M-1^{-/}$mice and $P$. acnes-injected wild-type mice. In the lung, there were only a few Foxp3-positive cells (data not shown), and statistical analysis could not be performed.

\section{Induced IL-10 Production in Tregs Is Not Detected in} ICAM-1 ${ }^{-/-}$Mice Compared with Wild-Type Mice after

\section{$P$. acnes Immunization}

Because there was no difference in the number of Tregs infiltrating into skin granuloma between $P$. acnes-injected
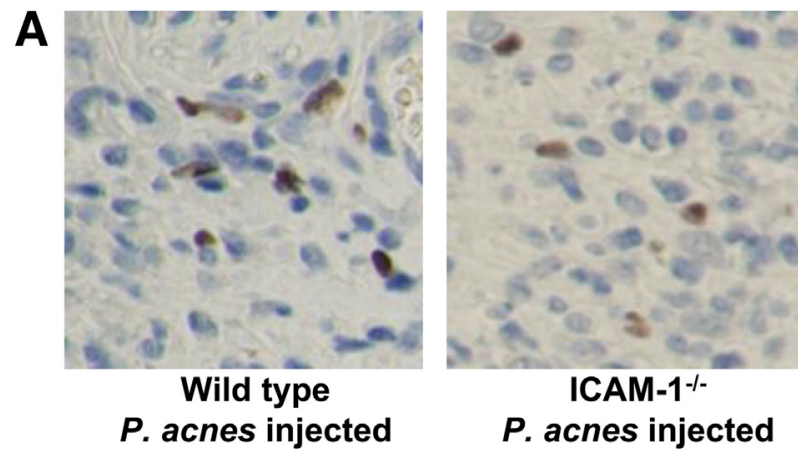

B

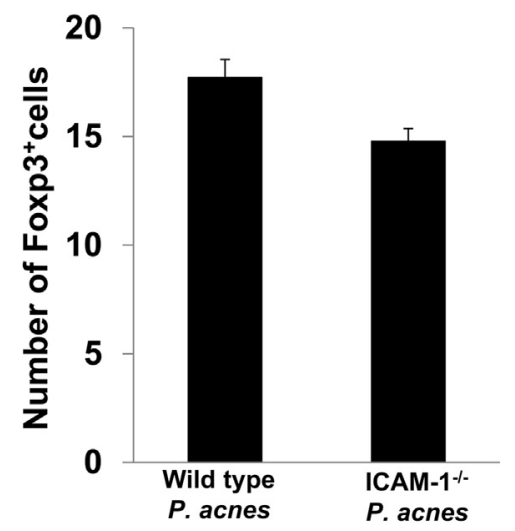

Figure 4 Infiltration of Foxp $3^{+}$Tregs into the skin granuloma of wild-type mice and ICAM-1 ${ }^{-1-}$ mice injected with $P$. acnes. A: Skin granuloma sections from $P$. acnes-injected mice were stained with anti-mouse Foxp3 Abs. B: The number of infiltrating Foxp $3^{+}$Tregs into the skin granuloma. Cells were counted in three random grids per mouse. Cells were counted in three random grids per mouse under magnification of $\times 400$ high-power fields. Data were obtained from six mice per group. Values are presented as means \pm SEM. Original magnification: $\times 600(\mathbf{A})$. 
ICAM $-1^{-/-}$mice and P. acnes-injected wild-type mice, we next examined IL-10 production induced by $P$. acnes immunization in these mice. In these experiments, bulk inguinal lymph node cells were stained with anti-CD4, $\mathrm{CD} 25$, and Foxp3 Abs, and $\mathrm{CD} 4{ }^{+} \mathrm{CD} 25^{+}$Foxp $3^{+}$cells were determined as Tregs. We first confirmed that CD11a, a component of LFA-1, the ligand for ICAM-1, was expressed on Tregs of $I C A M-1^{-/-}$mice at a level similar to wild-type mice (data not shown). To compare the IL-10 production capacity of $I C A M-1^{-/-}$and wild-type mice in the steady state, inguinal lymph node cells were isolated from PBS-injected ICAM-1 ${ }^{-1-}$ mice and PBS-injected wildtype mice and cultured overnight with $\mathrm{CD} 3$ and $\mathrm{CD} 28$ ligation. After culture, intracellular IL-10 expression in Tregs was analyzed by flow cytometry. There was no significant difference in IL-10 production capacity between PBS-injected ICAM-1 ${ }^{-1-}$ and PBS-injected wild-type mice (Figure 5A).

Next, lymph node cells were isolated from $P$. acnes-injected $I C A M-1^{-1-}$ mice and $P$. acnes-injected wild-type mice and cultured overnight with $\mathrm{CD} 3$ and CD28 ligation. After culture, intracellular IL-10 expression in Tregs was analyzed by flow cytometry. After $P$. acnes injection, Tregs from wild-type mice produced greater amounts of IL-10 compared with those from ICAM-1 ${ }^{-/-}$ mice (Figure 5B). In Tregs of wild-type mice, P. acnes injection induced IL-10 production compared with PBS injection (Figure 5C). In contrast, there was no such induction observed in Tregs of $P$. acnes-injected $I C A M-1^{-1-}$ mice (Figure 5D). Our results indicated that although the IL-10-producing capacity of Tregs was the same between wild-type mice and ICAM-1 $1^{-/}$mice in the steady state, $P$. acnes, which induced IL-10 production in Tregs of wildtype mice, failed to induce IL-10 production in Tregs of ICAM-1 ${ }^{-1-}$ mice.

\section{Discussion}

In the current study, we induced sarcoid-like granulomatosis in mouse skin and lungs by repeatedly injecting heat-killed $P$. acnes into the skin of wild-type mice. Histopathologic analysis revealed that granuloma formation was aggravated in both skin and lungs of $I C A M-I^{-/-}$mice compared with those of wild-type mice. As for E-selectin ${ }^{-1-}$ and Lselectin $^{-/-}$mice, granuloma formation was aggravated only in the lungs. P-selectin deficiency did not have any effect on granuloma formation. $P$. acnes immunization up-regulated TNF- $\alpha$ mRNA expression in skin granulomas of ICAM$1^{-/-}$mice compared with that of wild-type mice, whereas it failed to induce IL-10 mRNA expression in $I C A M-1^{-/-}$ mice. These data suggest that ICAM-1 might play a pivotal role in IL-10 induction during granuloma formation. Because Tregs are known as a major cell source of IL-10, we examined the effect of ICAM-1 on Treg recruitment and function. We did not detect any impairment of Treg recruitment into granuloma of $I C A M-1^{-/-}$mice. However, IL-10 production was induced by $P$. acnes immunization in $\mathrm{CD} 4{ }^{+} \mathrm{CD} 25^{+} \mathrm{Foxp}^{+}{ }^{+}$Tregs of wild-type mice but not in the Tregs of $I C A M-1^{-/-}$mice. Thus, our results indicate that
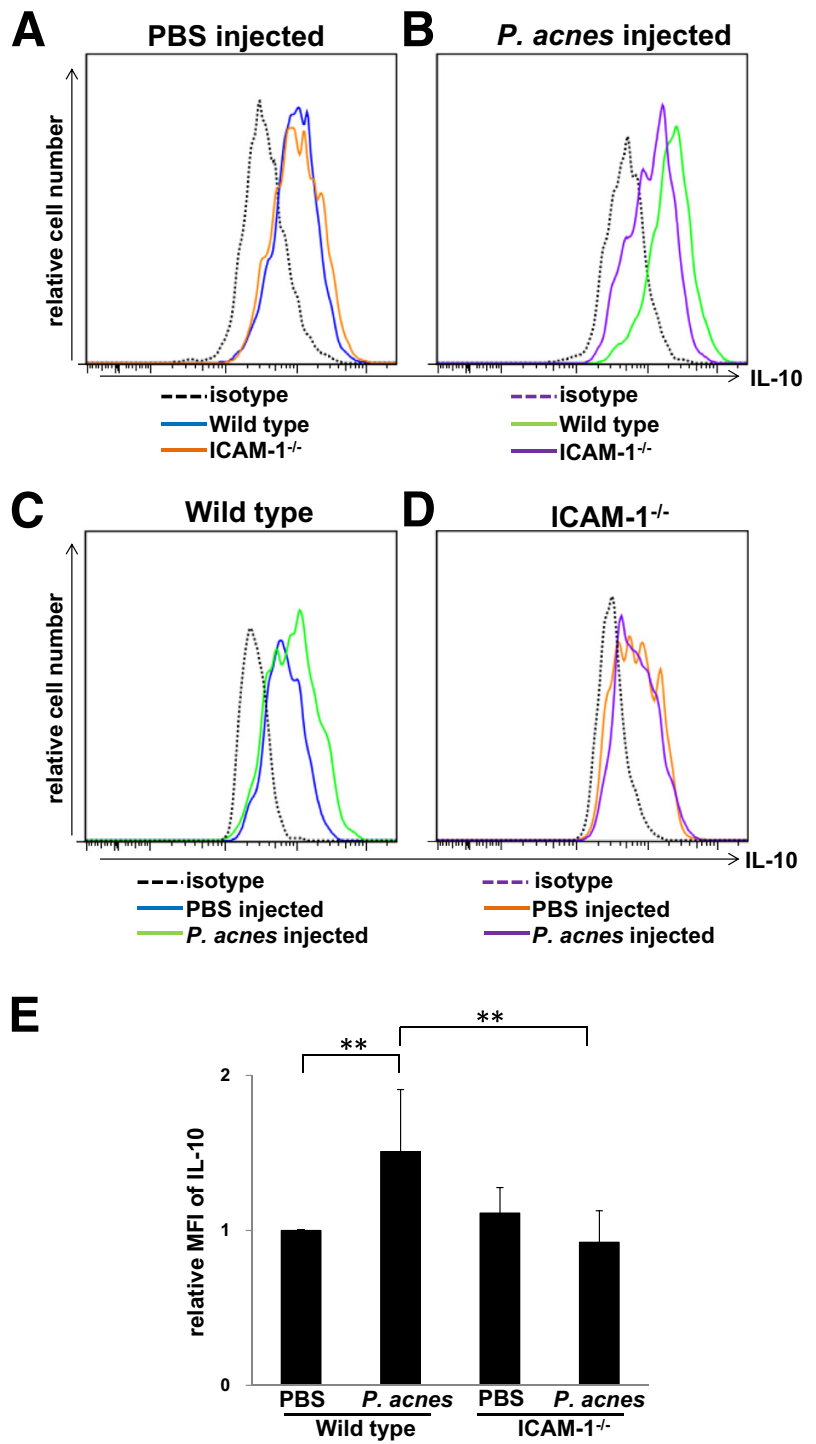

Figure 5 IL-10 production induced in $\mathrm{CD}^{+}{ }^{+} \mathrm{CD} 25^{+} \mathrm{Foxp}^{+}$Tregs after $P$. acnes injection is not detected in ICAM-1 $1^{-/}$mice compared with wild-type (WT) mice. Inguinal lymph nodes of mice injected with PBS or $P$. acnes were collected on day 28. Bulk lymph node cells were cultured for 2 days with CD3 and CD28 ligation. Cells were harvested, fixed, permeabilized, and stained with anti-IL-10 Abs or isotype control Abs. These cells were analyzed by flow cytometry. Comparison of intracellular IL-10 staining intensity between WT mice and ICAM-1 ${ }^{-1-}$ mice among PBS-injected mice $(\mathbf{A})$ and $P$. acnes-injected mice (B). Comparison of intracellular IL-10 staining intensity between PBSinjected mice and $P$. acnes-injected mice among WT mice (C) or ICAM-1 ${ }^{-1-}$ mice (D). The results shown are representative of five duplicated individual experiments. Mean fluorescence intensities (MFI) of anti-IL-10 mAb/isotype control stained Tregs were determined, and relative percentage (means \pm SD) was calculated in respective experiments according to the following formula and shown as a bar graph (E): (MFI of anti-IL-10 mAb-stained Tregs from each group of mice - MFI of isotype control Ab-stained Tregs from each group of mice)/(MFI of anti-IL-10 mAb-stained Tregs from PBS-injected WT mice MFI of isotype control Ab-stained Tregs from PBS-injected WT mice). Significant differences between samples are indicated $\left({ }^{* *} P<0.01\right)$. 
ICAM-1 is imperative for inducing the production of IL-10 in Tregs during granuloma formation in vivo, using the sarcoidosis mouse model.

The fact that granuloma formation was not confined to the skin injection site led us to consider that the skin granulomas observed in our study were not merely foreign-body granulomas. Nishiwaki et $\mathrm{a}^{15}$ have already made a murine pulmonary sarcoidosis model by injecting heat-killed $P$. acnes into the footpad every 2 weeks for a total of three or four times. In their experiments, immunohistochemical analyses revealed that the $\mathrm{CD}^{+} \mathrm{T}$ cells in granulomas expressed IFN- $\gamma$ but not IL-4, which are the Th1 cells, ${ }^{15}$ which is consistent with sarcoidosis. ${ }^{1,37}$ However, there was no verified murine model of cutaneous sarcoidosis yet. We induced skin granuloma that resembled sarcoidosis within 28 days by simply injecting heat-killed $P$. acnes into the mouse dorsal skin four times.

In sarcoidosis, it has been reported that activated $\mathrm{CD} 4^{+}$ cells differentiate into Th1-like cells that secrete predominantly IL- 2 and IFN- $\gamma$, augment TNF- $\alpha$ production by macrophages, and thereby amplify the local cellular immune response. ${ }^{38}$ Indeed, TNF- $\alpha$ mRNA expression was up-regulated in skin granuloma of $P$. acnes-injected wild-type mice compared with PBS-injected wild-type mice. Furthermore, TNF- $\alpha$ up-regulation was augmented in $P$. acnes-injected $I C A M-1^{-1-}$ mice, supporting the histopathologic findings that granuloma formation was aggravated in both skin and lungs of $P$. acnes-injected $I C A M-1^{-/-}$mice compared with P. acnes-injected wildtype mice.

Although IL-10 mRNA expression was up-regulated in skin granuloma of $P$. acnes-injected wild-type mice compared with PBS-injected wild-type mice, IL-10 mRNA expression was not detected in skin granuloma of $P$. acnes-injected $I C A M-1^{-1-}$ mice. Indeed, several reports indicated increased IL-10 expression in bronchoalveolar lavage fluid of patients with sarcoidosis. ${ }^{39,40}$ IL-10 inhibits the synthesis of various inflammatory cytokines, such as TNF- $\alpha$, and plays a major role in the regulation of immune responses as an inhibitor of $\mathrm{T}$-cell proliferation and macrophage activation. ${ }^{41-46}$ Therefore, decreased IL-10 mRNA expression could account for the increased TNF- $\alpha$ mRNA expression in skin granuloma of $P$. acnes-injected $I C A M-1^{-/-}$mice. One of the possible cell sources of IL-10 is the Treg, which suppresses T-cell proliferation and inflammation in the skin. ${ }^{47,48}$ Tregs are reported to be increased in patients with active granulomatous sarcoidosis lung. ${ }^{49}$ It has been suggested that despite extensive local inflammation, anergy in active sarcoidosis, as indicated by suppression of the immune response to tuberculin, is accounted for by expansion of Tregs, which abolishes IL-2 production and strongly inhibits T-cell proliferation. Together with our results, these reports led us to study the function of Tregs in $I C A M-1^{-/-}$mice.

LFA-1 (CD11a/CD18) is a component of the receptor for ICAM-1 and is expressed on leukocytes, including Tregs.
LFA-1 binds to ICAM-1 expressed on endothelial cells, which enables LFA-1-positive cells to transmigrate into tissues. ${ }^{50-52}$ We first confirmed that absence of ICAM-1 did not affect CD11a expression on Tregs (data not shown). We also confirmed that ICAM-1 deficiency did not affect Treg infiltration into skin granuloma by comparing the number of Foxp3-positive cells and the expression level of Foxp3 mRNA in granuloma because the Foxp3 gene has been identified as the master transcriptional factor of Tregs. ${ }^{53}$ These results suggest that ICAM-1 is not necessary for Tregs to infiltrate into the skin granuloma. This finding was consistent with the previous report that E- and P-selectin ligands expressed on Tregs are adhesion molecules necessary for their infiltration into the skin. ${ }^{54}$ Using a contact sensitivity model, Deane et $\mathrm{al}^{55}$ previously reported that endogenous Tregs adhered in inflamed dermal vessels via ICAM-1 were able to control adhesion of other proinflammatory leukocytes in vivo. Different from their observation within acute inflammation, Treg infiltration was not impaired in our chronic inflammatory sarcoidosis model using $I C A M-1^{-/-}$mice. However, it is still possible that during the acute phase of granuloma formation, there might have been a difference in Treg infiltration.

Sarcoidosis represents an unresolved immunologic paradox: affected organs are the staging ground for an intense immune response, yet at the same time, a state of anergy is established as indicated by suppression of immune response to tuberculin in sarcoidosis patients. Regarding this paradox, it was previously found that although Tregs accumulating at the periphery of sarcoid granuloma and in the peripheral blood exhibit powerful antiproliferative activity that may account for the state of anergy, these Tregs do not completely inhibit TNF- $\alpha$ production. ${ }^{56}$ Thus, our result indicates that ICAM-1 expression might be involved in the insufficiency of Tregs to control local inflammation in sarcoidosis.

In our study, the capacity of Tregs to produce IL-10 in the steady state was comparable between wild-type and ICAM $-1^{-/-}$mice. However, when these mice were immunized with $P$. acnes, although IL-10 production was induced in Tregs of wild-type mice, IL-10 production was not induced in Tregs of ICAM-1 ${ }^{-/-}$mice. Consistent with our result, Tran et $\mathrm{al}^{57}$ previously found that interaction between LFA-1 on Tregs and ICAM-1 on dendritic cells is critical for the suppressor function of Tregs. They first demonstrated that suppression of T-cell activation across species is highly efficient in vitro and is cell contact dependent. Then, by using responder $\mathrm{CD} 4^{+} \mathrm{T}$ cells from $I C A M-1^{-\prime-}$ mice, they demonstrated that human LFA-1 on Tregs specifically interacts with ICAM-1 on mouse dendritic cells rather than on the responder $\mathrm{T}$ cells and that this interaction is sufficient for suppression of $\mathrm{T}$ cell activation in vitro. ${ }^{57}$ Our study found, for the first time, that ICAM-1 is imperative for inducing Tregs to produce IL-10 in vivo, which would prevent chronic granuloma formation. 


\section{Supplemental Data}

Supplemental material for this article can be found at http://dx.doi.org/10.1016/j.ajpath.2013.08.021.

\section{References}

1. Newman LS, Rose CS, Maier LA: Sarcoidosis. N Engl J Med 1997, 336:1224-1234

2. Hua B, Li QD, Wang FM, Ai CX, Luo WC: Borrelia burgdorferi infection may be the cause of sarcoidosis. Chin Med J (Engl) 1992 , 105:560-563

3. Puolakkainen M, Campbell LA, Kuo CC, Leinonen M, GronhagenRiska C, Saikku P: Serological response to Chlamydia pneumoniae in patients with sarcoidosis. J Infect 1996, 33:199-205

4. Brownell I, Ramirez-Valle F, Sanchez M, Prystowsky S: Evidence for mycobacteria in sarcoidosis. Am J Respir Cell Mol Biol 2011, 45: 899-905

5. Gupta D, Agarwal R, Aggarwal AN, Jindal SK: Molecular evidence for the role of mycobacteria in sarcoidosis: a meta-analysis. Eur Respir J 2007, 30:508-516

6. Newman LS, Rose CS, Bresnitz EA, Rossman MD, Barnard J, Frederick M, Terrin ML, Weinberger SE, Moller DR, McLennan G Hunninghake G, DePalo L, Baughman RP, Iannuzzi MC, Judson MA, Knatterud GL, Thompson BW, Teirstein AS, Yeager H Jr., Johns CJ, Rabin DL, Rybicki BA, Cherniack R: A case control etiologic study of sarcoidosis: environmental and occupational risk factors. Am J Respir Crit Care Med 2004, 170:1324-1330

7. Chen ES, Moller DR: Sarcoidosis-scientific progress and clinical challenges. Nat Rev Rheumatol 2011, 7:457-467

8. Vokurka M, Lecossier D, du Bois RM, Wallaert B, Kambouchner M, Tazi A, Hance AJ: Absence of DNA from mycobacteria of the M. tuberculosis complex in sarcoidosis. Am J Respir Crit Care Med 1997, 156:1000-1003

9. Popper HH, Klemen H, Hoefler G, Winter E: Presence of mycobacterial DNA in sarcoidosis. Hum Pathol 1997, 28:796-800

10. Almenoff PL, Johnson A, Lesser M, Mattman LH: Growth of acid fast L forms from the blood of patients with sarcoidosis. Thorax 1996, $51: 530-533$

11. Baughman RP, Lower EE, du Bois RM: Sarcoidosis. Lancet 2003, $361: 1111-1118$

12. Eishi Y, Suga M, Ishige I, Kobayashi D, Yamada T, Takemura T, Takizawa T, Koike M, Kudoh S, Costabel U, Guzman J, Rizzato G, Gambacorta M, du Bois R, Nicholson AG, Sharma OP, Ando M: Quantitative analysis of mycobacterial and propionibacterial DNA in lymph nodes of Japanese and European patients with sarcoidosis. J Clin Microbiol 2002, 40:198-204

13. Yamada T, Eishi Y, Ikeda S, Ishige I, Suzuki T, Takemura T, Takizawa T, Koike M: In situ localization of Propionibacterium acnes DNA in lymph nodes from sarcoidosis patients by signal amplification with catalysed reporter deposition. J Pathol 2002, 198:541-547

14. Ishige I, Usui Y, Takemura T, Eishi Y: Quantitative PCR of mycobacterial and propionibacterial DNA in lymph nodes of Japanese patients with sarcoidosis. Lancet 1999, 354:120-123

15. Nishiwaki T, Yoneyama H, Eishi $\mathrm{Y}$, Matsuo N, Tatsumi $\mathrm{K}$, Kimura H, Kuriyama T, Matsushima K: Indigenous pulmonary Propionibacterium acnes primes the host in the development of sarcoidlike pulmonary granulomatosis in mice. Am J Pathol 2004, 165 631-639

16. Springer TA: Traffic signals for lymphocyte recirculation and leukocyte emigration: the multistep paradigm. Cell 1994, 76:301-314

17. Tedder TF, Steeber DA, Chen A, Engel P: The selectins: vascular adhesion molecules. FASEB J 1995, 9:866-873

18. Dustin ML, Rothlein R, Bhan AK, Dinarello CA, Springer TA: Induction by IL 1 and interferon-gamma: tissue distribution, biochemistry, and function of a natural adherence molecule (ICAM-1). J Immunol 1986, 137:245-254

19. Hogg N, Laschinger M, Giles K, McDowall A: T-cell integrins: more than just sticking points. J Cell Sci 2003, 116:4695-4705

20. Shimizu Y: LFA-1: more than just T cell Velcro. Nat Immunol 2003, 4:1052-1054

21. Verma NK, Dempsey E, Long A, Davies A, Barry SP, Fallon PG, Volkov Y, Kelleher D: Leukocyte function-associated antigen1/intercellular adhesion molecule-1 interaction induces a novel genetic signature resulting in T-cells refractory to transforming growth factor-beta signaling. J Biol Chem 2012, 287:27204-27216

22. Abraham C, Griffith J, Miller J: The dependence for leukocyte function-associated antigen-1/ICAM-1 interactions in T cell activation cannot be overcome by expression of high density TCR ligand. J Immunol 1999, 162:4399-4405

23. Hamaguchi Y, Nishizawa Y, Yasui M, Hasegawa M, Kaburagi Y, Komura K, Nagaoka T, Saito E, Shimada Y, Takehara K, Kadono T Steeber DA, Tedder TF, Sato S: Intercellular adhesion molecule-1 and L-selectin regulate bleomycin-induced lung fibrosis. Am J Pathol 2002, 161:1607-1618

24. Yanaba K, Komura K, Horikawa M, Matsushita Y, Takehara K, Sato S: P-selectin glycoprotein ligand-1 is required for the development of cutaneous vasculitis induced by immune complex deposition. J Leukoc Biol 2004, 76:374-382

25. Shimada Y, Hasegawa M, Kaburagi Y, Hamaguchi Y, Komura K, Saito E, Takehara K, Steeber DA, Tedder TF, Sato S: L-selectin or ICAM-1 deficiency reduces an immediate-type hypersensitivity response by preventing mast cell recruitment in repeated elicitation of contact hypersensitivity. J Immunol 2003, 170:4325-4334

26. Matsushita Y, Hasegawa M, Matsushita T, Fujimoto M, Horikawa M, Fujita T, Kawasuji A, Ogawa F, Steeber DA, Tedder TF, Takehara K, Sato S: Intercellular adhesion molecule-1 deficiency attenuates the development of skin fibrosis in tight-skin mice. J Immunol 2007, 179: 698-707

27. Frenette PS, Mayadas TN, Rayburn H, Hynes RO, Wagner DD: Susceptibility to infection and altered hematopoiesis in mice deficient in both P- and E-selectins. Cell 1996, 84:563-574

28. Bullard DC, Kunkel EJ, Kubo H, Hicks MJ, Lorenzo I, Doyle NA, Doerschuk CM, Ley K, Beaudet AL: Infectious susceptibility and severe deficiency of leukocyte rolling and recruitment in E-selectin and P-selectin double mutant mice. J Exp Med 1996, 183:2329-2336

29. Yanaba K, Kaburagi Y, Takehara K, Steeber DA, Tedder TF, Sato S: Relative contributions of selectins and intercellular adhesion molecule- 1 to tissue injury induced by immune complex deposition. Am J Pathol 2003, 162:1463-1473

30. Bullard DC, Mobley JM, Justen JM, Sly LM, Chosay JG, Dunn CJ, Lindsey JR, Beaudet AL, Staite ND: Acceleration and increased severity of collagen-induced arthritis in P-selectin mutant mice. J Immunol 1999, 163:2844-2849

31. Horikawa $M$, Fujimoto $M$, Hasegawa $M$, Matsushita $T$, Hamaguchi Y, Kawasuji A, Matsushita Y, Fujita T, Ogawa F, Takehara K, Steeber DA, Sato S: E- and P-selectins synergistically inhibit bleomycin-induced pulmonary fibrosis. Am J Pathol 2006, 169:740-749

32. Rosenkranz AR, Mendrick DL, Cotran RS, Mayadas TN: P-selectin deficiency exacerbates experimental glomerulonephritis: a protective role for endothelial P-selectin in inflammation. J Clin Invest 1999, 103:649-659

33. He X, Schoeb TR, Panoskaltsis-Mortari A, Zinn KR, Kesterson RA, Zhang J, Samuel S, Hicks MJ, Hickey MJ, Bullard DC: Deficiency of P-selectin or P-selectin glycoprotein ligand-1 leads to accelerated development of glomerulonephritis and increased expression of $\mathrm{CC}$ chemokine ligand 2 in lupus-prone mice. J Immunol 2006, 177: $8748-8756$

34. Parameswaran N, Suresh R, Bal V, Rath S, George A: Lack of ICAM-1 on APCs during T cell priming leads to poor generation of central memory cells. J Immunol 2005, 175:2201-2211 
35. Arbones ML, Ord DC, Ley K, Ratech H, Maynard-Curry C, Otten G, Capon DJ, Tedder TF: Lymphocyte homing and leukocyte rolling and migration are impaired in L-selectin-deficient mice. Immunity 1994, $1: 247-260$

36. Ashcroft T, Simpson JM, Timbrell V: Simple method of estimating severity of pulmonary fibrosis on a numerical scale. J Clin Pathol 1988, 41:467-470

37. Agostini C, Meneghin A, Semenzato G: T-lymphocytes and cytokines in sarcoidosis. Curr Opin Pulm Med 2002, 8:435-440

38. Zissel G, Prasse A, Muller-Quernheim J: Sarcoidosisimmunopathogenetic concepts. Semin Respir Crit Care Med 2007, 28:3-14

39. Rappl G, Pabst S, Riemann D, Schmidt A, Wickenhauser C, Schutte W, Hombach AA, Seliger B, Grohe C, Abken H: Regulatory $\mathrm{T}$ cells with reduced repressor capacities are extensively amplified in pulmonary sarcoid lesions and sustain granuloma formation. Clin Immunol 2011, 140:71-83

40. Barbarin V, Petrek M, Kolek V, Van Snick J, Huaux F, Lison D: Characterization of p 40 and IL-10 in the BALF of patients with pulmonary sarcoidosis. J Interferon Cytokine Res 2003, 23:449-456

41. Fiorentino DF, Bond MW, Mosmann TR: Two types of mouse T helper cell. IV Th2 clones secrete a factor that inhibits cytokine production by Th1 clones. J Exp Med 1989, 170:2081-2095

42. Fiorentino DF, Zlotnik A, Mosmann TR, Howard M, O'Garra A: IL-10 inhibits cytokine production by activated macrophages. J Immunol 1991, 147:3815-3822

43. Fiorentino DF, Zlotnik A, Vieira P, Mosmann TR, Howard M, Moore KW, O'Garra A: IL-10 acts on the antigen-presenting cell to inhibit cytokine production by Th1 cells. J Immunol 1991, 146: 3444-3451

44. Moore KW, Vieira P, Fiorentino DF, Trounstine ML, Khan TA, Mosmann TR: Homology of cytokine synthesis inhibitory factor (IL-10) to the Epstein-Barr virus gene BCRFI. Science 1990, 248: $1230-1234$

45. O'Garra A, Stapleton G, Dhar V, Pearce M, Schumacher J, Rugo H, Barbis D, Stall A, Cupp J, Moore K, Vieira P, Mosmann T, Whitmore A, Arnold L, Haughton G, Howard M: Production of cytokines by mouse B cells: B lymphomas and normal B cells produce interleukin 10. Int Immunol 1990, 2:821-832

46. de Waal Malefyt R, Abrams J, Bennett B, Figdor CG, de Vries JE: Interleukin 10 (IL-10) inhibits cytokine synthesis by human monocytes: an autoregulatory role of IL-10 produced by monocytes. J Exp Med 1991, 174:1209-1220

47. Asseman C, Mauze S, Leach MW, Coffman RL, Powrie F: An essential role for interleukin 10 in the function of regulatory $\mathrm{T}$ cells that inhibit intestinal inflammation. J Exp Med 1999, 190:995-1004

48. Ring S, Schafer SC, Mahnke K, Lehr HA, Enk AH: CD4+ CD25+ regulatory $\mathrm{T}$ cells suppress contact hypersensitivity reactions by blocking influx of effector T cells into inflamed tissue. Eur J Immunol 2006, 36:2981-2992

49. Mroz RM, Korniluk M, Stasiak-Barmuta A, Ossolinska M, Chyczewska E: Increased levels of Treg cells in bronchoalveolar lavage fluid and induced sputum of patients with active pulmonary sarcoidosis. Eur J Med Res 2009, 4(14 Suppl):165-169

50. Rothlein R, Dustin ML, Marlin SD, Springer TA: A human intercellular adhesion molecule (ICAM-1) distinct from LFA-1. J Immunol 1986, 137:1270-1274

51. Yang L, Froio RM, Sciuto TE, Dvorak AM, Alon R, Luscinskas FW: ICAM-1 regulates neutrophil adhesion and transcellular migration of TNF-alpha-activated vascular endothelium under flow. Blood 2005, 106:584-592

52. Marski M, Kandula S, Turner JR, Abraham C: CD18 is required for optimal development and function of $\mathrm{CD} 4+\mathrm{CD} 25+\mathrm{T}$ regulatory cells. J Immunol 2005, 175:7889-7897

53. Hori $\mathrm{S}$, Nomura T, Sakaguchi S: Control of regulatory $\mathrm{T}$ cell development by the transcription factor Foxp3. Science 2003, 299: 1057-1061

54. Dudda JC, Perdue N, Bachtanian E, Campbell DJ: Foxp3+ regulatory T cells maintain immune homeostasis in the skin. J Exp Med 2008, 205:1559-1565

55. Deane JA, Abeynaike LD, Norman MU, Wee JL, Kitching AR, Kubes P, Hickey MJ: Endogenous regulatory $\mathrm{T}$ cells adhere in inflamed dermal vessels via ICAM-1: association with regulation of effector leukocyte adhesion. J Immunol 2012, 188:2179-2188

56. Miyara M, Amoura Z, Parizot C, Badoual C, Dorgham K, Trad S, Kambouchner M, Valeyre D, Chapelon-Abric C, Debre P, Piette JC, Gorochov G: The immune paradox of sarcoidosis and regulatory $\mathrm{T}$ cells. J Exp Med 2006, 203:359-370

57. Tran DQ, Glass DD, Uzel G, Darnell DA, Spalding C, Holland SM, Shevach EM: Analysis of adhesion molecules, target cells, and role of $\mathrm{IL}-2$ in human FOXP3 + regulatory $\mathrm{T}$ cell suppressor function. J Immunol 2009, 182:2929-2938 